\title{
Pro-apoptotic Effects of S100A8 and S100A9 on human FIP1L1-PDGFR $\alpha+$ Eosinophilic Leukemia Cells
}

\author{
Ji-Sook Lee ${ }^{\dagger ; *}$ \\ Department of Clinical Laboratory Science, Wonkwang Health Science University, Iksan 54538, Korea
}

The S100 family proteins act as inducers of cancer cell apoptosis and inflammatory mediators. This study examined the pro-apoptotic mechanism caused by S100A8 and S100A9 in human FIP1L1-PDGFR $\alpha$-positive eosinophilic leukemia cells. S100A8 and S100A9 elicited the death of EoL-1 cells in a time and dose-dependent manner. The activation of PDGFR $\alpha$ was suppressed by a decrease in PDGFR $\alpha$ after treatment with S100A8 and S100A9. Cycloheximide, a translation inhibitor, suppressed PDGFR $\alpha$ expression from $1 \mathrm{~h}$ to $5 \mathrm{~h}$, and a co-treatment with S100A8 and S100A9 boosted the decrease in expression. The phosphorylation and expression of STAT5 decreased after treatment with S100A8 and S100A9 in EoL-1 and imatinib-resistant (EoL-1-IR) cells. S100A8 and S100A9 induced the chemotaxis of EoL-1 cells but did not affect the chemoattraction of EoL-1-IR. These findings indicate the cell death mechanism due to S100 family proteins and the development of leukemia therapy using S100A8 and S100A9.

Key Words: S100, FIP1L1-PDGFR $\alpha$, Chronic eosinophil leukemia

S100A8 and S100A9 function as overarching factors in cell death on top of inflammation (Donato et al., 2013; Bresnick et al., 2015). S100A8 and S100A9 have bidirectional effects, depending on different situations; both proteins support cell survival or trigger cell death (Kim et al., 2017; Kim and Lee, 2018). In addition to the roles of extracellular S100A8 and S100A9, intracellular S100A8 or S100A9 acts as a scavenger of reactive oxygen species (ROS) and enhances the telomerase activity after calcium binding (Goyette and Geczy, 2011). S100A8 and S100A9 were reported to suppress the survival of chronic eosinophilic leukemia cells and cause cell apoptosis (Lee et al., 2020). This study investigated the mechanisms further to consolidate the apoptosis of chronic eosinophilic leukemia cells. EoL-1 cells were purchased from the Ricken Cell Bank (Tsukuba,
Japan) and cultured in RPMI 1640 containing 10\% fetal bovine serum and antibiotics. Imatinib-resistant EoL-1 cells (EoL-1-IR) were stably established after a consecutive treatment with $100 \mathrm{nM}$ imatinib (Sigma-Korea, Seoul, Korea) for at least six months. The survival rate of the Eol-1-IR cells was more than $90 \%$ in the presence of $100 \mathrm{nM}$ imatinib. Patients with acute myeloid leukemia (AML) $(n=2)$ were recruited from the Eulji Medical Center (IRB No. 2017-06022). The leukocytes were isolated from the peripheral blood using Ficoll-Hypaque solution. A previous study used the RNAs from unstimulated EoL-1 cells in RT-PCR to detect FIP1L1-PDGFR (Lambert et al., 2007). The primer sequences used are as follows: forward 5'-ACC TGG TGC TGA TCT TTC TGA T-3' and reverse 5'-TGA GAG CTT GTT TTT CAC TGG A-3' in the first PCR, and forward 5'-

Received: April 16, 2021 / Revised: June 10, 2021 / Accepted: June 14, 2021

* Professor.

${ }^{\dagger}$ Corresponding author: Ji-Sook Lee. Department of Clinical Laboratory Science, Wonkwang Health Science University, 501, Iksandaero, Iksan 54538, Korea. Tel: +82-63-840-1216, Fax:+82-63-840-1219, e-mail: jslee1216@wu.ac.kr

(C) The Korean Society for Biomedical Laboratory Sciences. All rights reserved.

(C) This is an Open Access article distributed under the terms of the Creative Commons Attribution Non-Commercial License (http://creativecommons.org/licenses/by-nc/3.0/) which permits unrestricted non-commercial use, distribution, and reproduction in any medium, provided the original work is properly cited. 
AAA GAG GAT ACG AAT GGG ACT TGT G-3' and reverse 5'-GGG ACC GGC TTA ATC CAT AG-3' in the second round of PCR. Recombinant S100A8 and S100A9 proteins were produced using the protocol described elsewhere (Lee et al., 2020). The survival rate was evaluated using an MTT assay (Thermo Scientific, Waltham, MA, USA). For Western Blotting, the cells were lysed in CETi lysis buffer (TransLab, Daejeon, Korea), and the lysate was collected. The protein concentration of the lysate was evaluated using a BCA protein assay kit (Thermo Scientific) according to the manufacturer's instructions. The cell lysates were loaded on the gel, resolved by SDS-PAGE, and transferred to nitrocellulose membranes. The blots were incubated with the primary and secondary antibodies, and the developed blots were visualized by Chemidoc (Bio-Rad, Hercules, CA, USA). A cell migration assay was performed

(A)

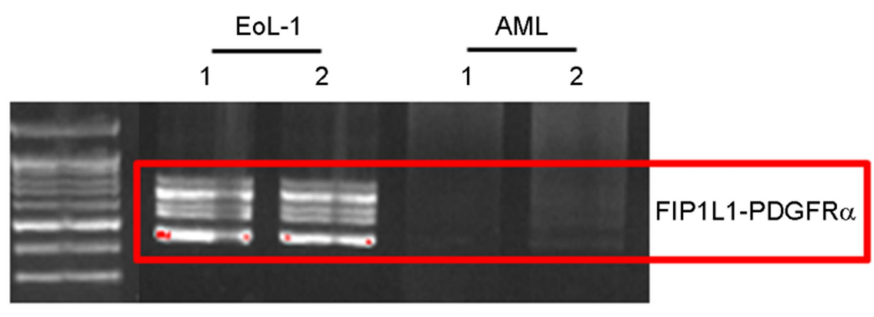

B

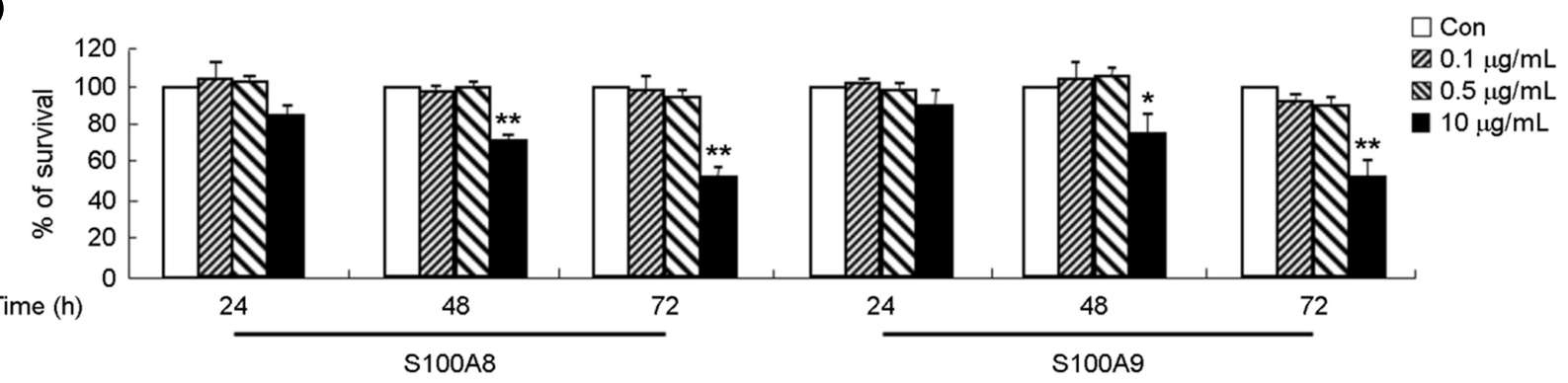

C
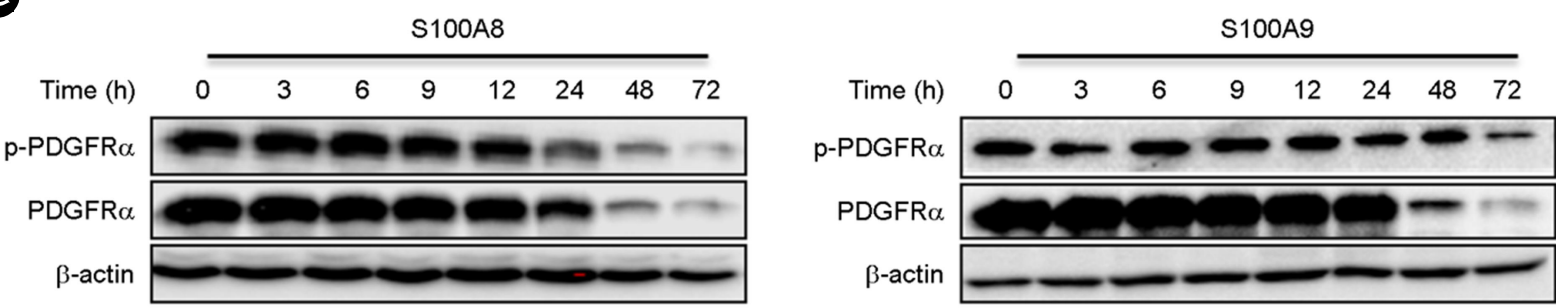

D

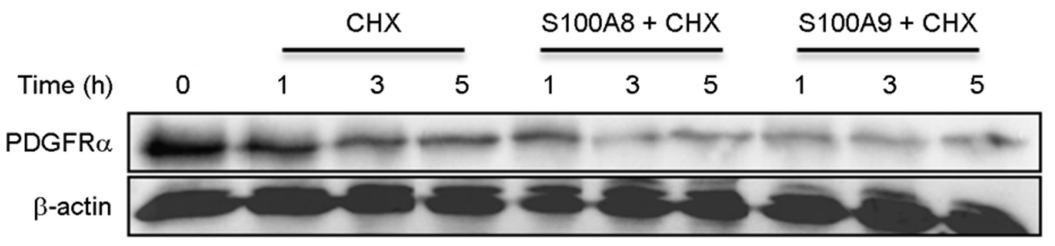

Fig. 1. S100A8 and S100A9 suppress the expression and phosphorylation of PDGFRa in EoL-1 cells. (A). The total RNAs from EoL-1 cells were collected, and RT-PCR was conducted to detect the FIPIL1-PDGFR $\alpha$ gene. (B) EoL-1 cells were incubated with S100A8 and S100A9 at the indicated concentrations for the indicated time. The survival rate of the cells was evaluated using an MTT assay. $* P<0.05$ and ${ }^{* *} P<0.01$ indicate a significant difference between the control and stimulator-treated groups. (C and D) EoL-1 cells were pretreated without (C) or with (D) cycloheximide (CHX) and then incubated with S100A8 and S100A9 $(10 \mu \mathrm{g} / \mathrm{mL})$ for the indicated time. Expression of the indicated proteins was evaluated using Western blotting. $\mu$-actin was used as the internal control. 
A

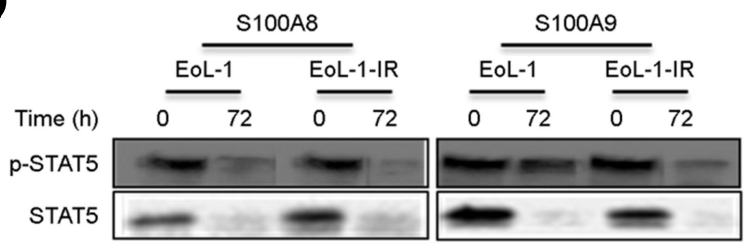

B

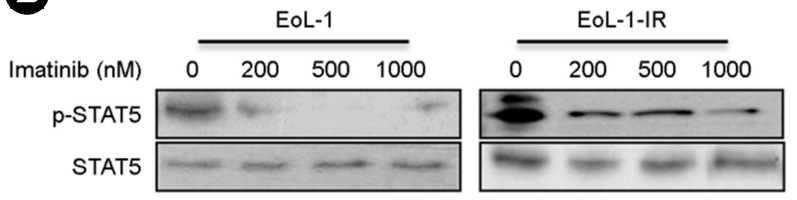

Fig. 2. S100A8 and S100A9 inhibits the expression and phosphorylation of STAT5 in EoL-1 and EoL-1-IR cells. (A and B) EoL-1 and EoL-1-IR cells were incubated with S100A8, S100A9 $(10 \mu \mathrm{g} / \mathrm{mL})(\mathrm{A})$, and imatinib (indicated concentration) (B) for $72 \mathrm{~h}$. Phosphorylation and expression of STAT5 were evaluated using Western blotting.

using a 48-well microchamber (Neuroprobe, Cabin John, MD) as previously elsewhere (Kim et al., 2005). PBS, S100A8, S100A9, or MCP-1 (R\&D Systems, Minneapolis, MN, USA) were added to the lower wells. A fibronectincoated polyvinylpyrrolidone-free filter (Neuroprobe) with $5 \mu \mathrm{m}$ pores was placed on the lower wells, and the upper wells were filled with $50 \mu \mathrm{L}$ of EoL-1 and EoL-1-IR cells at $4 \times 10^{6}$ cells $/ \mathrm{mL}$. The chamber was then incubated for $5 \mathrm{~h}$ in a $\mathrm{CO}_{2}$ incubator. The filter was detached and stained with Giemsa stain (Sigma-Korea). The cells adhering to the lower surface of the polycarbonate filter were considered migrated cells and counted using a microscope. The EoL-1 cells were confirmed by the detection of the FIPIL1-PDGFR $\alpha$ gene (Fig. 1A). No expression of the fusion gene was observed in the leukocytes separated from AML subjection. The previous paper showed that S100A8 and S100A9 induce EoL-1 cell apoptosis (Lee et al., 2020). In this study, cell death was confirmed by an MTT assay, which matches with a previous one (Fig. 1B). S100A8 and S100A9 suppress the phosphorylation of PDGFR- $\alpha$ by decreasing PDGFR- $\alpha$ expression in a time-dependent manner (Fig. 1C). PDGFR$\alpha$ expression decreased gradually from $1 \mathrm{~h}$ to $5 \mathrm{~h}$ after a treatment with cycloheximide (Fig. 1D). Treatment with S100A8 and S100A9 blocked the expression more effectively during the inhibitory state of protein synthesis. This

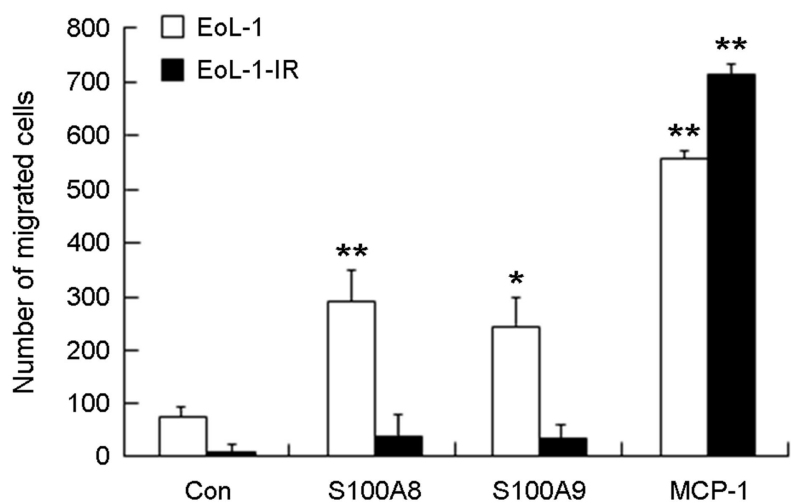

Fig. 3. S100A8 and S100A9 elicit EoL-1 cell migration. EoL-1 and EoL-1-IR cells were treated with PBS (Con), S100A8 $(1 \mu \mathrm{g}$ $\mathrm{mL}), \mathrm{S} 100 \mathrm{~A} 9(0.1 \mu \mathrm{g} / \mathrm{mL})$ and MCP-1 $(10 \mathrm{ng} / \mathrm{mL})$ in a 48 -well microchamber and allowed to move for $5 \mathrm{~h}$. The number of migrated cells was counted under a microscope. $* P<0.05$ and $* * P<0.01$ indicate a significant difference between the control and stimulatortreated groups.

finding suggests that S100A8 and S100A9 are strongly related to the downregulation of PDGFR- $\alpha$ translation. The changes in the activation and expression of STAT 5, which is an important factor in the regulation of apoptosis, were examined to find another pro-apoptotic mechanism for S100A8 and S100A9 (Wu et al., 2012). S100A8 and S100A9 blocked the expression and phosphorylation of STAT5 in EoL-1 and EoL-1-IR cells (Fig. 2A). Imatinib, a potent inhibitor of leukemia cell survival (Qu et al., 2016), suppressed STAT5 activation without changing STAT5 expression (Fig. 2B). The effects of S100A8 and S100A9 on STAT5 alteration may be accomplished using a different mechanism compared to imatinib (Fig. 3). If a stimulator is chemotactic to cancer cells and an inhibitor of cell survival, it can act as a powerful drug for cancer treatment. A chemotaxis assay was performed to determine the cell migration in response to S100A8 and S100A9. Both proteins are effective on EoL-1 cell migration. On the other hand, they had no effect on EoL-1-IR. Although S100A8 and S100A9 may induce the apoptosis of EoL-1 cells after chemoattracting the cells, they were effective on the apoptosis of imatinib-resistant cells without the induction of cell migration. The difference between both cells may be derived from different protein expression (Sung et al., 2018). 


\section{ACKNOWLEDGEMENT}

This paper was supported by Wonkwang Health Science University in 2021.

\section{CONFLICT OF INTEREST}

The authors have no conflicts of interest, financial or otherwise, to declare.

\section{REFERENCES}

Bresnick, AR, Weber DJ, Zimmer DB. S100 proteins in cancer. Nature Review Cancer. 2015. 15: 96-109.

Donato R, Cannon BR, Sorci G, et al. Functions of S100 proteins. Current Molecular Medicine. 2013. 13: 24-57.

Goyette J, Geczy CL. Inflammation-associated S100 proteins: new mechanisms that regulate function. Amino Acids. 2011. 41: 821-842.

Kim IS, Jang SW, Sung HJ, Lee JS, Ko J. Differential CCR1mediated chemotaxis signaling induced by human $\mathrm{CC}$ chemokine HCC-4/CCL16 in HOS cells. FEBS Letters. 2005. 579: 6044-6048.

Kim IS, Lee JS. S100A8 and S100A9 secreted by allergens in monocytes inhibit spontaneous apoptosis of normal and asthmatic neutrophils via the Lyn/akt/ERK pathway. Korean Journal of Clinical Laboratory Science. 2017. 49: 128-134.

Kim IS, Lee JS. The pro-apoptotic effects of S100A8 and S100A9 in human monocytic leukemia cells, THP-1. Biomedical
Science Letters. 2018. 24: 134-137.

Lambert F, Heimann P, Herens C, Chariot A, Bours V. A case of FIP1L1-PDGFRA-positive chronic eosinophilic leukemia with a rare FIP1L1 breakpoint. Journal of Molecular Diagnostics. 2007. 9: 414-419.

Lee JS, Lee NR, Kashif A, et al. S100A8 and S100A9 promote apoptosis of chronic eosinophilic leukemia cells. Frontiers in Immuology. 2020. 11: 1258.

Qu SQ, Qin TJ, Xu ZF, et al. Long-term outcomes of imatinib in patients with FIP1L1/ PDGFRA associated chronic eosinophilic leukemia: experience of a single center in China Oncotarget. 2016. 7: 33229-33236.

Sung KH, Kim IS, Lee JS. Different protein expression between human eosinophilic leukemic cells, EoL-1 and imatinibresistant EoL-1 cells, EoL-1-IR. Biomedical Science Letters. 2018. 24: 426-429.

Wu Y, Chen C, Sun X, Shi X. Cyclin-dependent kinase 7/9 inhibitor SNS-032 abrogates FIP1-like-1 platelet-derived growth factor receptor $\alpha$ and bcr-abl oncogene addiction in malignant hematologic cells. Clinical Cancer Research. 2012. 18: 19661978

https://doi.org/10.15616/BSL.2021.27.2.95

Cite this article as: Lee JS. Pro-apoptotic Effects of S100A8 and S100A9 on human FIP1L1-PDGFR $\alpha+$ Eosinophilic Leukemia Cells. Biomedical Science Letters. 2021. 27: 95-98. 